\title{
Evaluation of surface water dynamics for water-food security in seasonal wetlands, north-central Namibia
}

\author{
TETSUYA HIYAMA ${ }^{1}$, TETSUJI SUZUKI ${ }^{2}$, MIHO HANAMURA ${ }^{2}$, \\ HIROKI MIZUOCHI ${ }^{3}$, JACK R. KAMBATUKU ${ }^{4}$, JOHANNA N. NIIPELE ${ }^{4}$, \\ YUICHIRO FUJIOKA ${ }^{5}$, TAKESHI OHTA ${ }^{2} \&$ MORIO IIJIMA $^{5}$
}

1 Hydrospheric Atmospheric Research Center, Nagoya University, Nagoya, Japan hiyama@hyarc.nagoya-u.ac.jp

2 Graduate School of Bioagricultural Sciences, Nagoya University, Nagoya, Japan

3 Graduate School of Life and Environmental Sciences, University of Tsukuba, Tsukuba, Japan

4 Faculty of Agriculture and Natural Resources, University of Namibia, Oshakati, Namibia

5 Faculty of Agriculture, Kinki University, Nara, Japan (co-affiliation: JST/JICA, SATREPS, Japan)

\begin{abstract}
Agricultural use of wetlands is important for food security in various regions. However, land-use changes in wetland areas could alter the water cycle and the ecosystem. To conserve the water environments of wetlands, care is needed when introducing new cropping systems. This study is the first attempt to evaluate the water dynamics in the case of the introduction of rice-millet mixed-cropping systems to the Cuvelai system seasonal wetlands (CSSWs) in north-central Namibia. We first investigated seasonal changes in surface water coverage by using satellite remote sensing data. We also assessed the effect of the introduction of rice-millet mixed-cropping systems on evapotranspiration in the CSSWs region. For the former investigation, we used MODIS and AMSR-E satellite remote sensing data. These data showed that at the beginning of the wet season, surface water appears from the southern (lower) part and then expands to the northern (higher) part of the CSSWs. For the latter investigation, we used data obtained by the classical Bowen ratio-energy balance (BREB) method at an experimental field site established in September 2012 on the Ogongo campus, University of Namibia. This analysis showed the importance of water and vegetation conditions when introducing mixed-cropping to the region.
\end{abstract}

Key words Cuvelai system seasonal wetlands (CSSWs); flood- and drought-adaptive cropping system (FDACS); Bowen ratio-energy balance (BREB) method; water environments

\section{INTRODUCTION}

Wetlands cover $6 \%$ of the Earth's land surface and have great hydrological and ecological importance. Agricultural use of wetlands is important for food security in various regions. However, land-use changes in wetland areas could alter evapotranspiration, a major component of the water balance, which could eventually affect the water cycle and ecosystems (Suzuki et al. 2013). To conserve the water environments of wetlands, care is needed when introducing new cropping systems. From the socio-ecological point of view, harmonisation between development and environmental conservation is a universal issue in the 21 st century. Particularly in semi-arid regions of Africa, where food scarcity is a serious problem, there is the risk of rapid and disorderly agricultural development without consideration of the environment. In recent years, semi-arid regions of sub-Saharan Africa have been struck periodically by severe droughts as well as severe floods, which have caused food shortages in the region.

Namibia, located in southern Africa, has an area of $824000 \mathrm{~km}^{2}$, a population of about 2364000 , and a gross national income (GNI) per capita of 4510 USD (The World Bank 2012). With its rich mineral resources, Namibia's economic growth was $4.8 \%$ per year on average from 2009 to 2010 (The World Bank 2012). However, Namibia is one of the least equitable countries in the world, as shown by a Gini index from 64 to 74 (United Nations Development Programme 2007, The World Bank 2012).

A quarter of the population lives in north-central Namibia, where most residents are subsistence farmers cropping pearl millet and raising livestock. Mean annual precipitation in the region is about $400 \mathrm{~mm}$. The wet season starts in the middle of October and ends in the middle of April of the next year. The dry season extends from mid-April to mid-October. In the wet season, surface (flood) water flows from the Angolan Plateau and creates a vast seasonal wetland covering approximately 800000 ha. The region is locally called the Cuvelai system seasonal wetlands (CSSWs) (Njunge 
2013). The amount of flood water has varied widely in the last 10 years, causing serious deluge or drought in the region.

The water resources of the CSSWs are currently used mainly for grazing and fishing, and not for cropping. The limited use of these water resources is due to the unstable flood intensity and because the Etosha Pan in the southern part of the CSSWs is a national wildlife sanctuary. If largescale agricultural development were to occur in this region, the vulnerable wetland environment might be harmed (Kambatuku et al. 2013).

Since 2011, we have been conducting research aimed at developing a flood- and droughtadaptive cropping system (FDACS) that can preserve water environments and cope with yearly fluctuations in rainfall. The FDACS will be developed through trials in the fields of crop science, development studies, hydrology, and integrated studies. This paper mainly focuses on the hydrology aspects. The purposes of this study are: (1) to understand surface flooding around the CSSWs, and (2) to assess the effects of the introduction of rice-millet mixed-cropping systems on evapotranspiration in the region.

\section{METHODS}

To achieve research purpose (1), we used satellite remote sensing data of the Moderate Resolution Imaging Spectroradiometer (MODIS) and the Advanced Microwave Scanning Radiometer-Earth Observing System (AMSR-E). Using data from these two sensors, we investigated seasonal changes in surface water coverage over the CSSWs. For research purpose (2), we newly established two Bowen ratio-energy balance (BREB) measuring systems in an experimental research field at Ogongo campus, University of Namibia (UNAM). This field site is located near the centre of the CSSWs at Oshakati, Namibia $\left(17^{\circ} 40^{\prime} 49.02^{\prime \prime} \mathrm{S}, 15^{\circ} 18^{\prime} 10.83^{\prime \prime} \mathrm{E}\right)$.

\section{Satellite remote sensing analyses}

We estimated spatiotemporal variations in surface water-covered (flooded) areas (locally called "oshanas") over north-central Namibia, including in the CSSWs. Two indices were used to determine the surface water-covered area: the normalised difference water index (NDWI) and the normalised difference polarisation index $(N D P I)$.

The NDWI is defined by the following equation:

$$
N D W I=\frac{\rho_{\text {red }}-\rho_{\text {SWIR }}}{\rho_{\text {red }}+\rho_{\text {SWIR }}}
$$

where $\rho_{\text {red }}$ and $\rho_{\text {SWIR }}$ are the reflectance of the red $(0.6-0.7 \mu \mathrm{m})$ and shortwave infrared $(1.4-3.0 \mu \mathrm{m})$ electromagnetic spectrum bands (spectral regions), respectively.

The NDPI is defined as:

$$
N D P I=\frac{36.5_{T v}-36.5_{T h}}{36.5_{T v}+36.5_{T h}}
$$

where $36.5_{T v}$ and $36.5_{T h}$ are the brightness temperature $(\mathrm{K})$ of the vertically and horizontally polarised $36.5 \mathrm{GHz}$ microwave, respectively (Sippel et al. 1994, Takeuchi et al. 2006).

The NDWI was calculated using MODIS visible and infrared band data at 250-m spatial resolution (16-day composite MOD13Q1 and MYD13Q1 data). The NDPI was determined from AMSR-E microwave radiometer data at $25-\mathrm{km}$ resolution. Both MODIS and AMSR-E are carried on the Aqua satellite launched on 4 May 2002. Another MODIS is carried on the Terra satellite, which was launched on 18 December 1999.

Firstly, by using MODIS data, we obtained a relationship of reflectance between the red and shortwave infrared spectral regions. Then, $N D W I=-0.1$ was determined as the threshold for differentiation between a water surface and other land surfaces. On the basis of these analyses, the probability of the existence of surface water was obtained during nine years (2003-2011; $\mathrm{n}=414$; where $\mathrm{n}$ is the number of samples). However, because MODIS cannot observe land surface conditions under cloud cover, a common condition during the wet season, obtaining a high temporal 
resolution (e.g. daily) NDWI mapping was difficult. Thus, the daily NDWI map was complemented using the cloud-free NDPI map. Finally, we were able to estimate the daily surface water coverage map from 2003 to 2011.

\section{Bowen ratio-energy balance (BREB) measurement}

We established two BREB systems (upper and lower sites) at the beginning of September 2012 in an experimental sloped field within the Ogongo campus, UNAM. Both systems included an albedo meter (CHF-SRA01, Hukseflux, The Netherlands), a net radiometer (CPR-NR-LITE, Kipp \& Zonen, The Netherlands), two sets of air temperature-humidity sensors (CVS-HMP-155D, Vaisala, Finland), a heat flux plate (CHF-HFP-01, Campbell Scientific Inc., USA), three sets of soil temperature sensors (C-PTWP-10, Climatec Inc., Japan), three sets of water temperature sensors (C-PTWP-10, Climatec Inc., Japan), three sets of soil moisture sensors (C-CS-616-7.5, Campbell Scientific Inc., USA), and a water level sensor (CWG-H10-C20-NGH, Climatec Inc., Japan). We additionally installed a wind speed-direction sensor (CYG-3002, Young, Japan) to one of the systems (upper slope site) and a wind speed sensor (CYG-3102, Young, Japan) to the other system (lower slope site).

Using the following equations, we determined sensible and latent heat fluxes at both sites in the sloped field:

$$
\begin{aligned}
& \beta=\frac{c_{p}}{l}\left[\frac{\operatorname{Ta}\left(z_{1}\right)-T a\left(z_{2}\right)}{q\left(z_{1}\right)-q\left(z_{2}\right)}\right]=\frac{H}{l E} \\
& H=\frac{\beta}{1+\beta}(R n-G) \\
& l E=\frac{1}{1+\beta}(R n-G)
\end{aligned}
$$

Here, $T a$ is air temperature, $q$ is specific humidity, $c_{p}$ is the specific heat at constant pressure, $l$ is the latent heat for vaporization, $R n$ is the net radiation, $G$ is the soil heat flux, $H$ is the sensible heat flux, $l E$ is the latent heat flux, and $\beta$ is the Bowen ratio. The subscripts 1 and 2 denote the different measurement heights $(z)$ of the air temperature-humidity sensors.

Several other environmental variables were also measured by using the BREB systems. The main variables used in this study were downward shortwave radiation $(S d)$, upward shortwave radiation $(S u)$, surface albedo $(\alpha)$, soil water content $(S W C)$, ground (soil) temperature $(T g)$, and precipitation $(P r)$.

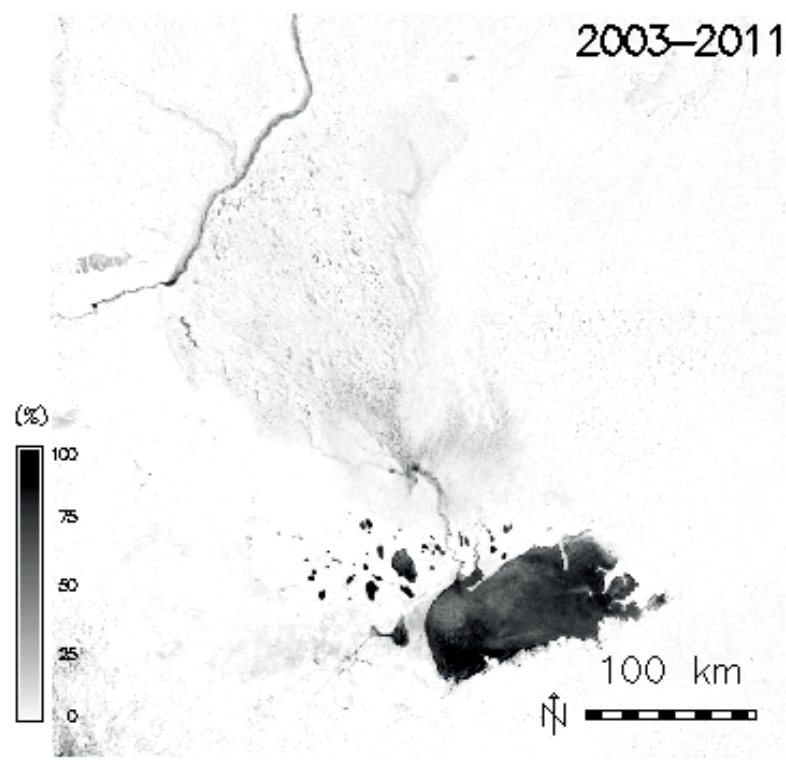

Fig. 1 Spatial distribution of the probability of the existence of surface water around the CSSWs obtained using the $N D W I$. 


\section{RESULTS AND DISCUSSION}

\section{Seasonal changes in surface water coverage over the CSSWs}

Figure 1 shows the spatial variation in the probability of the existence of surface water around the CSSWs obtained from the NDWI during 2003-2011 $(\mathrm{n}=414)$. It should be noted that surface water appeared in the lower (southern) part of the CSSWs around early January and propagated to the upper (northern) part of the CSSWs toward the middle of March. However, the origin of the surface water remains uncertain. The water might have originated from a combination of rainfall, surface runoff (flood water) from the Angolan Plateau flowing through seasonal rivers (oshanas), and groundwater discharge.

The CSSWs include not only seasonal rivers (oshanas) but also small-scale wetlands (ondombes), which are patchily distributed over uplands (higher gap surfaces among seasonal rivers). It is recommended that FDACS be introduced to ondombes (not oshanas) because local farmers can easily utilise ondombes for their own productive activities. The spatial scale of ondombes is mostly less than $500 \mathrm{~m}$. Thus, because of the limited spatial resolution of MODIS, the probability distribution of water-covered areas (Fig. 1) mainly shows the existence of surface water in seasonal rivers (oshanas). Further study of the coincidence of surface water between oshanas and ondombes is needed.

Our field observations to date suggest that the surface (pond) water of ondombes originates from rainfall and/or groundwater, not from the overland surface flow of oshanas. For more precise water budget evaluations, it is necessary to clarify the spatial distribution of rainfall as well as that of groundwater levels (and/or the groundwater characteristics of ondombes and the surface water features of oshanas). Monitoring of the spatiotemporal distributions of rainfall, surface runoff, evapotranspiration, and groundwater depth is recommended.

We have established BREB systems in the experimental sloped field at Ogongo campus of UNAM, allowing for evaluation of the difference in evapotranspiration between pearl milletdominated crop fields and rice-dominated crop fields after the introduction of FDACS. This topic is evaluated in the next section.

\section{Effect on evapotranspiration of introducing a mixed cropping system}

Figure 2 shows time series (from mid-September 2012 to mid-April 2013) in air temperature ( $T a$ ), vapour pressure deficit $(V P D)$, wind speed $(W s)$, daytime evapotranspiration $(E T)$, and precipitation $(P r)$ observed at the upper (millet-dominated) and lower (rice-dominated) sites of the sloped experimental field of Ogongo campus, UNAM. There are no significant differences in $T a, V P D$, and $W s$ between the upper and lower sites. At both sites, $T a$ and $V P D$ decreased after the rainy season began. After flooding of the lower field, evapotranspiration $(E T)$ at this field became higher than that at the upper site. After the rainy season began, ET at the lower site became small, mainly because of the decrease in $T a$ and $V P D$. After planting rice and pearl millet, $E T$ at the lower (rice) site increased again probably due to the contribution from rice cropping.

Very little rain fell during the 2012-2013 wet season around the CSSWs. Even pearl millet, a drought-tolerant crop, suffered in this severe drought. Crops at the upper site of the experimental sloped field failed during this drought. Thus, the upper site had almost no vegetation and was covered by bare soil surface. In contrast, the lower site was irrigated artificially, and the rice crop grew successfully. These surface conditions affected the energy (radiation and heat) budget in the fields.

Figure 3 shows time series of net radiation $(R n)$, sensible heat flux $(H)$, latent heat flux $(l E)$, and surface albedo $(\alpha)$ together with $P r$ at both sites. After flooding at the lower site, both $R n$ and $l E$ became higher at the lower site than at the upper site. On the other hand, $\alpha$ and $H$ became higher at the upper site. These radiation and heat budgets were controlled mainly by water and vegetation conditions. Thus, the effects of water level, soil moisture, and vegetation densities on the surface energy budget as well as the ET characteristics should be analysed in the near future. 

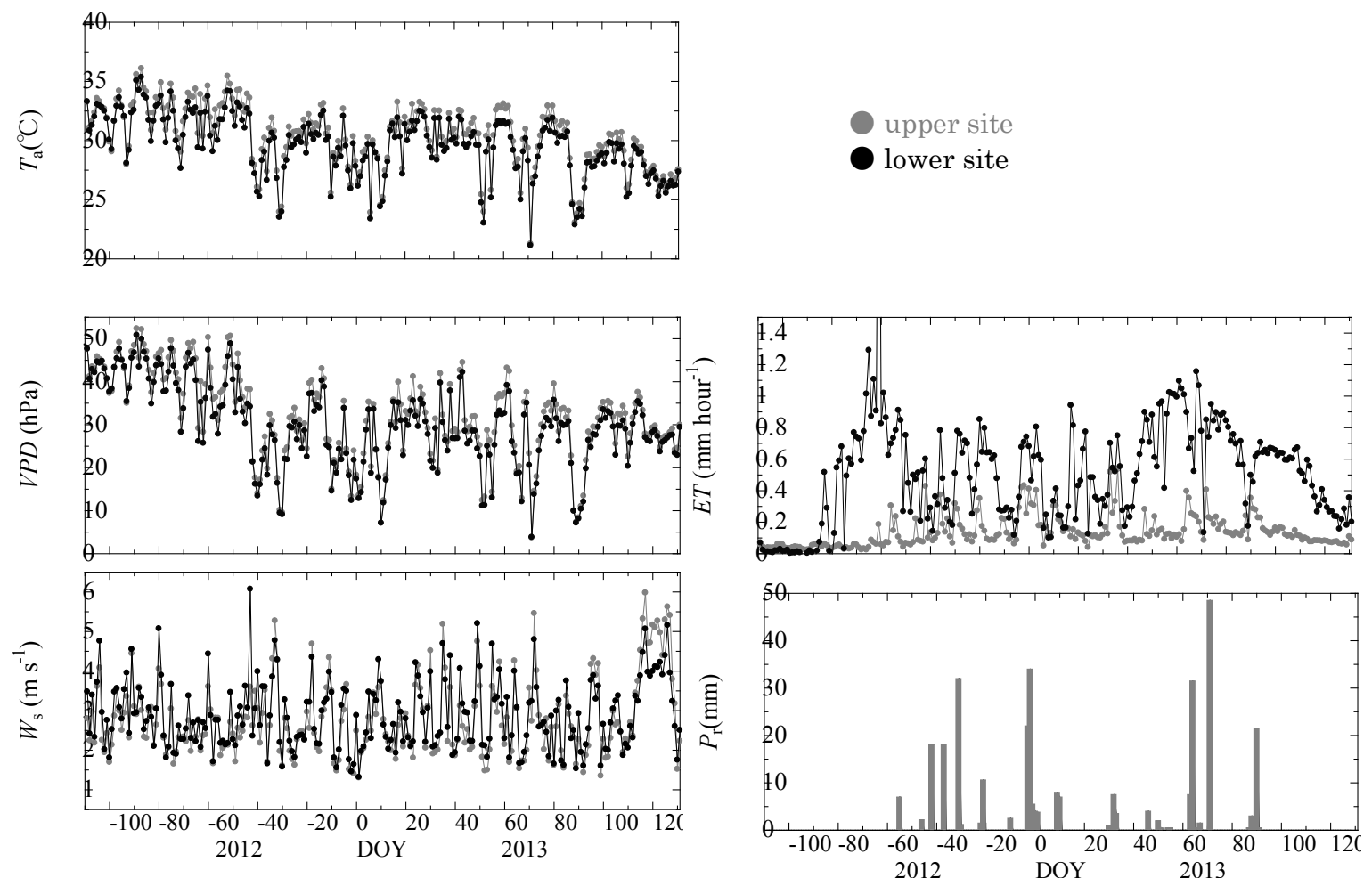

Fig. 2 Time series of air temperature $(T a)$, vapour pressure deficit $(V P D)$, wind speed $(W S)$, daytime evapotranspiration $(E T)$, and precipitation $(P r)$ at the upper and lower sites of the sloped experimental field at Ogongo campus, University of Namibia (UNAM). DOY is the day of the year 2013. (DOY 1 means 1 January 2013.)
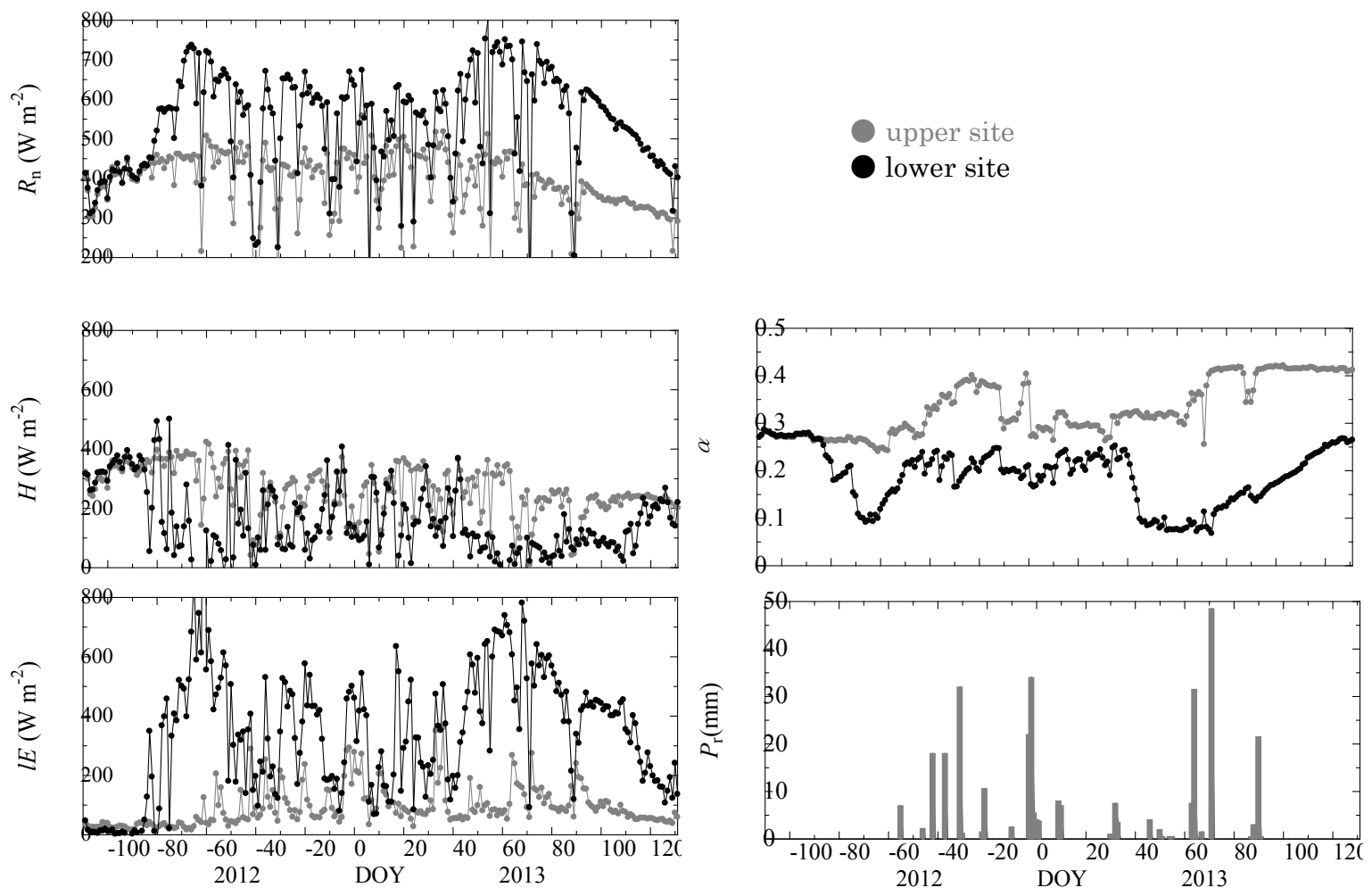

Fig. 3 Same as Fig. 2 but for net radiation $(R n)$, sensible heat flux $(H)$, latent heat flux $(l E)$, surface albedo $(\alpha)$, and precipitation $(P r)$. 


\section{CONCLUSIONS}

The CSSWs have the highest human population densities in Namibia $\left(50-100\right.$ people $\left./ \mathrm{km}^{2}\right)$. The small wetlands (ondombes) are used partly for pastoralism and also for numerous individual family settlements and townships. This study is the first attempt to evaluate the water dynamics for water security in the case of the introduction of rice-millet mixed-cropping systems (FDACS) to ondombes in the CSSWs in north-central Namibia. The purposes of this study were: (1) to understand surface flooding water around the CSSWs, and (2) to assess the effects on evapotranspiration of introducing mixed-cropping systems in the region.

Two main results relating to these objectives were obtained:

(1) Regarding seasonal changes in hydrology, analysis of MODIS and AMSR-E satellite remote sensing data revealed that surface water first begins to appear in the southern (lower) part of the CSSWs.

(2) Data obtained by two BREB systems, which were established in September 2012 in an experimental research field at Ogongo campus of the UNAM, showed the importance of water and vegetation conditions for the introduction of FDACS to the ondombes.

Acknowledgements This study was supported by an international research/development (R/D) project of the Science and Technology Research Partnership for Sustainable Development (SATREPS) entitled "Flood- and drought-adaptive cropping systems to conserve water environments in semi-arid regions" (P.I.: M. Iijima). We thank the Japan Science and Technology Agency (JST) and the Japan International Cooperation Agency (JICA) for their kind coordination. We also thank all members of the Faculty of Agriculture and Natural Resources, University of Namibia (UNAM), for kindly collaborating with our research.

\section{REFERENCES}

Kambatuku, J. R., et al. (2013) Regional precipitation patterns and their implication for drought-adapted mixed cropping systems in the Cuvelai Drainage Basin, North-Central Namibia. In: Proceedings for the International Symposium of SATREPS RiceMahangu Project "Agricultural Use of Seasonal Wetland Formed in Semiarid Region of Africa", 13 July 2013, Nagoya University, Japan, 47-54.

Njunge, J. T. (2013) Natural vegetation and potential agroforestry use of the seasonal wetlands in North, Central Namibia. In: Proceedings for the International Symposium of SATREPS Rice-Mahangu Project "Agricultural Use of Seasonal Wetland Formed in Semiarid Region of Africa", 13 July 2013, Nagoya University, Japan, 21-29.

Sippel, J. S., et al. (1994) Determination of inundation area in the amazon river floodplain using the SMMR 37 GHz polarization difference. Remote Sensing of Environment 48, 70-76.

Suzuki, T., et al. (2013) Effects of the introduction of rice on evapotranspiration in seasonal wetlands. Hydrological Processes doi:10.1002/hyp.9970.

Takeuchi, A., Yasuoka, Y. and Oki, T. (2006) Improvement on a spatio-temporal resolution on rice paddy inundation mapping with MODIS and AMSR-E. Proceedings of 2006 Fall Conference of the Japan Society of Photogrammetry and Remote Sensing 3-4.

The World Bank (2012) World Development Indicators 2012. The World Bank, 430 p.

United Nations Development Programme (2007) Human Development Report 2007/2008. Fighting climate change: Human solidarity in a divided world. Palgrave Macmillan, New York, 384p. 